\title{
Genome-wide identification, expression and chromosomal location of the genes encoding chitinolytic enzymes in Zea mays
}

\author{
Michal Shoresh • Gary E. Harman
}

Received: 20 March 2008 / Accepted: 29 May 2008 / Published online: 17 June 2008

(C) Springer-Verlag 2008

\begin{abstract}
Chitinolytic enzymes are important pathogenesis and stress related proteins. We identified 27 putative genes encoding endochitinases in the maize genome via in silico techniques and four exochitinases. Only seven of the endochitinases and segments of the exochitinases were heretofore known. The endochitinases included members of family 19 chitinases (classes I-IV of PR3, II of PR4) and members of family 18 chitinases (class III of PR8). Some similar enzymes were detected on adjacent regions of the same chromosome, and seem to result from duplication events. Most of the genes expressed were identified from EST libraries from plants exposed to biotic or abiotic stresses but also from libraries from tissues not exposed to stresses. We isolated proteins from seedlings of maize in the presence or absence of the symbiotic root colonizing fungus Trichoderma harzianum strain T22, and analyzed the activity of chitinolytic enzymes using an in-gel activity assay. The activity bands were identified by LC/MS/MS using the database from our in silico study. The identities of the enzymes changed depending on whether or not T22 was present. One activity band of about $95 \mathrm{kDa}$ appeared to be a heterodimer between an exochitinase and any of several different endochitinases. The identity of the endochitinase component appeared to be dependent upon treatment.
\end{abstract}

Communicated by C. Gebhardt.

M. Shoresh · G. E. Harman

Department of Horticultural Sciences,

Cornell University, Geneva, NY 14456, USA

M. Shoresh $(\varangle)$

Institute of Soil, Water, and Environmental Sciences,

The Volcani Center, P.O. Box 6, 50250 Bet Dagan, Israel

e-mail: michalsho@volcani.agri.gov.il
Keywords Zea mays - Trichoderma harzianum .

Chitinolytic enzymes · Pathogenesis-related (PR) proteins

\section{Introduction}

Chitinolytic enzymes occur in different functional forms. According to Enzyme Nomenclature, the word chitinase (endo- $\beta$ - $N$-acetylglucosaminidase; EC 3.2.1.14) refers to endochitinases that cleave the chitin chain randomly. In addition, exochitinases ( $\beta$ - $N$-acetylhexosaminidases; EC 3.2.1.52) cleave $N$-acetylglucosamine (GlcNAc) (they may also act upon other hexosamine polymers) residues from the non-reducing end of the chitin molecule. Chitinases therefore catalyze the hydrolytic cleavage of the $\beta$-1,4-glucoside bonds present in biopolymers of GlcNAc, mainly in chitin (Kasprzewska 2003). GlcNAc is also present as a component of the sugar chain of glycoproteins and glycolipids in plants. GlcNAc also constitutes signal molecules that function in the interaction of plants with microorganisms; such molecules include $N$-acetyl-chitooligosaccharide elicitors (Ishihara et al. 1988) for plant defense against pathogens and Nod factors (Geurts and Franssen 1996) that initiate symbiotic reactions with Rhizobial bacteria in leguminous plants. Hereafter, to avoid confusion, enzymes that cleave the chitin chain internally will be designated endochitinases, the $\beta-N$-acetylhexosaminidases that cleave residues from the non-reducing end of the substrate polymer will be designated exochitinases and any chitin-degrading enzyme, whether exo or endo acting, will be designated a chitinolytic enzyme.

Chitinolytic enzymes are considered to be pathogenesisrelated (PR) proteins since their activity can be induced by fungal, bacterial and viral infections and elicitors from fungal sources. They can also be induced by more general 
sources of stress such as wounding, salicylic acid, ethylene, auxins and cytokinins and heavy metal salts (Bravo et al. 2003; Kasprzewska 2003). The enzymes may be strongly antifungal (Schlumbaum et al. 1986; Mauch et al. 1988; Huynh et al. 1992; Lorito et al. 1993a, b, c; SelaBuurlage et al. 1993; Lorito et al. 1994). Overexpression, or high level expression, of heterologous chitinolytic enzymes alone or in combination with other antifungal proteins frequently results in protection against pathogens (Lorito et al. 1996, 1998; Bolar et al. 2000, 2001). The enhanced protection by the chitinases could be due to direct inhibition of fungal growth or due to induction of plant defense responses by the GlcNAc oligomers generated by their activity (Ishihara et al. 1988). However, in other studies modulation of chitinase expression did not change the plant resistance to pathogens (Neuhaus et al. 1991a; Samac and Shah 1994). This suggests that chitinases may also have other roles, such as involvement in plant development. For example, it was shown that chitinases could rescue the carrot somatic embryo mutant $t s 11$ (Baldan et al. 1997). A possible correlation was also demonstrated between increased vigour and chitinase activity in tobacco (Patil and Widholm 1997). An endogenous substrate for plant chitinases has not yet been definitively identified. However, there is strong evidence that these enzymes catalyze the hydrolytic decomposition of arabinogalactan proteins (AGPs) present in plants (van Hengel et al. 2001, 2002). Other $N$-acetylglucosamine-containing glycoproteins present in the cell wall may be endogenous substrates for plant chitinases (Berger et al. 1995; Schultze et al. 1998; van der Holst et al. 2001; Dyachok et al. 2002). It has also been suggested that exochitinases have probable roles in the degradation of reserve glycoproteins during seed germination (Poulton et al. 1985) and $N$-glycan metabolism during ripening in apple fruit (Choi and Gross 1994).

According to the glycosyl hydrolase classification system that is based on amino acid sequence similarity of the catalytic domains, endochitinases have been placed in families 18 and 19 (Henrissat 1991). Family 18 enzymes are found in bacteria, fungi, yeast, viruses, plants and animals, whereas family 19 members are almost exclusively present in plants. These enzymes have further been grouped into seven different classes on the basis of their structural and functional properties (Neuhaus 1999; Passarinho and de Vries 2002; Yokoyama and Nishitani 2004). These belong to three groups of PR proteins. Group PR3 includes endochitinases of classes I, II, IV, VI and VII, group PR8 includes class III endochitinases and PR11 includes class V endochitinases. Additionally, some PR proteins with low endochitinase activity were found (Neuhaus 1999; Kasprzewska 2003). Only classes III and IV belong to family 19 endochitinases. In the rice genome, 44 endochitinases were identified of which 16 belong to family 18 and 28 belong to family 19 (Yokoyama and Nishitani 2004). However, when we examined the maize databases, we found only seven endochitinases and four exochitinases. This clearly was an underestimation of the number of chitinolytic enzymes in maize.

This was important to us since we had shown that both exo- and endochitinase activity increased in maize seedlings grown from seeds treated with the biocontrol fungus Trichoderma harzianum $\mathrm{T} 22$ and that this increase in chitinase activity was systemic throughout the plant (Harman et al. 2004b; Harman and Shoresh 2007). This increase in activity was associated with increased resistance to foliar leaf pathogens (Harman et al. 2004b). Similar results have been reported for a wide range of biocontrol interactions (Harman et al. 2004a; Shoresh et al. 2005). Therefore, in order to assess the numbers and types of chitinolytic enzymes in maize we needed to identify the chitinolytic enzymes present in this plant.

The purposes of the present study were (a) to identify in silico from the maize EST expression databases the genes encoding chitinolytic enzymes from maize, (b) to assemble the EST data for genes thus discovered into contigs and to conduct domain analysis to verify results, (c) to determine expression of the genes encoding chitinolytic enzymes in our Trichoderma-maize biological system and (d) to map the resulting chitinolytic enzymes to their chromosomal locations using mapping data from EST expression libraries.

\section{Materials and methods}

Gene family study

Maize sequences were retrieved by searching the NCBI database (http://www.ncbi.nlm.nih.gov/UniGene/lbrowse2. cgi?TAXID=4577) and Maize GDB (http://www.maizegdb. org/) for genes annotated as maize chitinases. We manually removed duplications, retaining only unduplicated sequences. In addition to fully annotated genes, we retrieved ESTs and other non-annotated sequences by comparing the chitinases we found to nucleotide and protein sequences by BLAST analysis of maize sequences. ESTs and partial cDNAs were assembled into contigs using CAP3 software (http:// bioweb.pasteur.fr/seqanal/interfaces/cap3.html). Whenever putative cDNA lacked either the initial or terminal exon, we retrieved genomic sequences by performing BLAST analysis on genomic sequences at Maize GDB, and assembled these into putative genes using FGENESH+ (http://linux 1.softberry.com/berry.phtml?topic=fgenes_plus\& group=programs\&subgroup=gfs) and GENSCAN softwares (http://genes.mit.edu/GENSCAN.html). Sequences were 
aligned and compared using ClustalX (http://bips.u-strasbg. $\mathrm{fr} / \mathrm{fr} /$ Documentation/ClustalX/). Domain analysis was performed using InterProScan (http://www.ebi.ac.uk/ InterProScan/) and cellular localization was predicted by using TargetP 1.1 (http://www.cbs.dtu.dk/services/TargetP/), PSORT (http://psort.nibb.ac.jp/) and ProtComp Version 6 (http://softberry.com/berry.phtml?topic=protcomp\&group= help\&subgroup=proloc). BLAST algorithms were used to compare maize sequences with rice and Arabidopsis sequences. The EST libraries in maize are organized according to the tissue from which they were isolated, as is the prevalence of isolation of the EST in question. This permitted us to identify the specific location/conditions where specific maize chitinolytic enzymes are expressed and to make some estimates regarding expression level. The gene linkage maps for specific ESTs allowed us to map the genes to their chromosomal location and to examine that specific chromosomal location for duplications. Phylogenetic relationships of the chitinases were calculated using the Neighbour Joining method of Saitou and Nei using ClustalW (1.8) and viewed using TreeView (win32) 1.6.6 (http://taxonomy.zoology.gla.ac.uk/rod/treeview.html).

\section{Plant assays}

For the experimental phase of the project, seeds of maize (Zea mays L.) inbred Mo17 were treated with T. harzianum Rifai strain 22 (T22) in a cellulose-dextran formulation $\left(1-2 \times 10^{9} \mathrm{cfu} / \mathrm{g}\right)$ as described previously (Harman and Custis 2006) or were treated with water. Application of the cellulose-dextran powder without T22 gave no observable change in plant growth (data not shown). The celluloseTrichoderma powder was suspended in water $(38.5 \mathrm{mg} /$ $5 \mathrm{ml}$ ) and $100 \mu \mathrm{l}$ were applied to $5 \mathrm{~g}$ of seeds. Treated seeds were planted in sandy loam field soil in boxes $(10.5 \times$ $10.5 \times 6 \mathrm{~cm}$ ), five seeds per box. Boxes were incubated in a growth chamber with diurnal fluorescent lighting with 16/ $8 \mathrm{~h}$ (light/dark cycle), at $22 \pm 4^{\circ} \mathrm{C}$, and watered as needed. Seven-day-old seedlings were harvested: shoot heights were measured and then the shoots were excised at the soil level. Roots were carefully removed from the soil, omitting the region containing the germinated seed, and then gently washed (Harman et al. 2004b). All tissues were immediately frozen in liquid nitrogen and stored at $-70^{\circ} \mathrm{C}$ until used.

\section{Protein extraction}

Shoot tissue samples were ground with liquid nitrogen followed by further grinding in $9 \mathrm{ml}$ of ice cold $0.1 \mathrm{M}$ HEPES; $2 \%$ dithiothreitol (DTT) per $3 \mathrm{~g}$ tissue powder in Ultra-Turrax homogenizer (Janke \& Kunkel). A total of $20 \mathrm{~g}$ shoots were processed for each treatment and pooled to form two repeats. For ca. $10 \mathrm{~g}$ of control plants, 55 plants were used. For Trichoderma-treated plants, 40 plants were used to obtain ca. $10 \mathrm{~g}$ of tissue. The homogenate was then centrifuged for $20 \mathrm{~min}$ at $15,000 \mathrm{rpm}$ at $4^{\circ} \mathrm{C}$. Proteins were precipitated from the supernatant by adding eight volumes of ice-cold acetone and incubating $16 \mathrm{~h}$ at $-20^{\circ} \mathrm{C}$. After similar centrifugation, the precipitated proteins were washed twice with $2 \mathrm{ml}$ of ice-cold acetone followed by drying under a flow of $\mathrm{N}_{2}$. The resulting powder was then dissolved in sample solubilization buffer [100 mM sodium acetate ( $\mathrm{pH}$ 5.5), $10 \mathrm{mM}$ ethylenediaminetetraacetic acid (EDTA), $0.1 \mathrm{mM}$ DTT]. A small aliquot was diluted 50-fold with water and the protein content was determined using Coomassie Plus Protein Assay (Pierce) according to manufacturer's instructions.

PAGE and in-gel chitinase activity assay

SDS-polyacrylamide gel electrophoresis (SDS-PAGE) was used to separate protein samples. Protein samples were mixed with loading buffer $[15 \%$ sucrose, $2.5 \%$ SDS, 125 mM Tris-HCl (pH 6.7), 0.01\% Bromo-phenol Blue] and treated at $55^{\circ}$ or $100^{\circ} \mathrm{C}$ for $5 \mathrm{~min}$ and then separated on a $12 \%$ acrylamide gel in a Mighty Small II electrophoresis system (Amersham). The gels were washed in renaturation buffer [ $40 \mathrm{mM}$ Tris-HCl (pH 9.0), $2 \mathrm{mM}$ EDTA, $1 \%$ casein] for $30 \mathrm{~min}$ and this was repeated twice. The gels were then equilibrated for $20 \mathrm{~min}$ in $100 \mathrm{mM}$ sodium acetate buffer ( $\mathrm{pH} 5.0)$ containing $1 \%(\mathrm{~V} / \mathrm{V})$ purified Triton$\mathrm{X} 100$. This was followed by two washes with $100 \mathrm{mM}$ sodium acetate buffer ( $\mathrm{pH}$ 5.0) for 15 min each. Method for chitinase renaturation in SDS-PAGE gels and after boiling was described in Trudel and Asselin $(1989,1994)$.

Gels were then stained for chitinase activity by overlaying with $1 \%$ low melting $\left(\leq 35^{\circ} \mathrm{C}\right.$ gelation temperature) agarose that contained methylumbelliferyl substrates in $100 \mathrm{mM}$ acetate buffer (pH 5.0). Substrates used were 4-methylumbelliferyl- $N$-acetyl- $\beta$-D-glucosaminide (MUA; $20 \mathrm{ng} / \mathrm{ml}), \quad 4$-methylumbelliferyl- $N$-acetyl- $\beta$-D- $N, N^{\prime}$-diacetylchitobioside (MUB; $16.6 \mathrm{ng} / \mathrm{ml}$ ), 4-methylumbelliferyl $-N$ acetyl- $\beta$-D- $N, N^{\prime}, N^{\prime \prime}$-triacetylchitotrioside (MUC; $10 \mathrm{ng} / \mathrm{ml}$ ) and 4-methylumbelliferyl $N$-acetyl- $\beta$-D $-N, N^{\prime}, N^{\prime \prime} N^{\prime \prime \prime}$-tetraacetylchitotetraoside (MUD; $10 \mathrm{ng} / \mathrm{ml}$ ) (Sigma, St Louis, MO). The agarose mixture was melted in a microwave oven and kept in a water bath at $37^{\circ} \mathrm{C}$ and substrates were added prior to application. Gels were kept at room temperature and the activity bands were observed after 2, 10 and 30 min under UV light. After photography of the chitinase activity banding patterns, the agarose layer was gently removed and the gel was rinsed in deionized water and stained for protein profiles and validation of equal loading by Coomassie Brilliant Blue R-250 (Eastman Kodak). 
Mass-spectrometry analysis and protein identification

Bands with chitinolytic activity were cut from gels and were identified by peptide sequencing using nanospray iontrap tandem mass spectrometry (nESI-IT MS/MS) after digestion of proteins with trypsin. Proteins were separated using an LC Packings (Dionex)/4000 Q Trap (Applied Biosystems) in positive ion mode. Protein identification was carried out using the PMF-GPS Explorer, ESI-Analyst (Applied Biosystems) software. Databases produced by our in silico gene identification were primarily used in the search, with supplemental information from the non-redundant NCBI (National Center for Biotechnology Information, W) and SwissProt (European Bioinformatics Institute, Heidelberg, Germany) databases. Searches were performed in the full range of $M \mathrm{r}$ and $\mathrm{p} I$.

\section{Results}

Identification of maize chitinase genes

To identify the maize chitinases including those involved in plant-Trichoderma interactions, we first examined annotated known sequences that can be retrieved from maize sequences in the literature. As noted earlier, only a few sequences were identified for chitinolytic enzymes in maize. However, 25 and 44 endochitinases were identified in rice and Arabidopsis, respectively (Passarinho and de Vries 2002; Yokoyama and Nishitani 2004). We used published rice and Arabidopsis sequences to BLAST search the abundant EST and genome databases from maize. Using key words based search and sequence comparisons, 27 endochitinase genes were retrieved. All of those chitinases were classified and found to belong to classes I, II, and IV of PR3, II of PR4 and III of PR8 (Table 1). In addition, four exochitinases were identified (Table 1).

Examination of the genomic databases enabled identification of the chromosome on which most (22 endochitinases and three exochitinases) of the genes are located (Table 1). In some cases, related genes reside in adjacent positions on the same chromosome. For example, ChiI11654 and ChiI93771 are both on chromosome 6 (between positions ca. 113,000146,000 and 30,800-32,000 of their accessions, respectively). ChiII96529 and ChilI67336 are both on chromosome 1 (between positions ca. 104,000-106,000 and 100,000102,000 of their accessions, respectively). ChilII2139 and ChiIII21556 are both on chromosome 7 (between positions ca. 154,000-156,000 and 16,000-18,000 of their accessions, respectively). All of the PR4-class II genes are located on chromosome 4. The ChilI-PR4 and ChilI-drp genes each appear as duplicates. ChilI-PR4 duplications are between positions ca. 94,600-95,500 and 112,100-113,000 in acces- sion AC204382.2 (indicated in Table 1 as ChilI-PR4 and ChilI-PR4b). In unigene Zm.2227, some ESTs are identical to ChiII-PR4 and some are identical to ChilI-PR4b indicating that $\mathrm{Zm} .2227$ contains sequences from the two genes. ChiIIdrp and drpb are located on chromosome 4 between positions 133,000-133,900 and 152,200-153,100 of the accession AC204382.2. The genomic region of ChiIVA also contained a gene duplication (positions ca. 116,000-118,000 and 89,000-91,000). While the first copy was 97\% identical (within the error of sequencing) to ChilVA, the second copy had only $85 \%$ identity to this gene. By gene modeling, ChilVC was constructed (Table 1).

Four exo genes (ZmExo1-4) were found in databases (gi: 21209897, 54653093, 21209061, and 21216992). However, all lacked the amino terminus of the proteins. This was built for all except for ZmExo4 from their corresponding genomic sequences, which were identified by BLAST and contig analysis. ZmExo3 and ZmExo4 are very similar (82\% similarity at the protein level) but they are located on separate chromosomes (Table 1). ZmExo1 is similar to these two (67 and $60 \%$ to $\mathrm{ZmExo3}$ and $\mathrm{ZmExo} 4$, respectively) and $\mathrm{ZmExo} 2$ is the most dissimilar (45, 47 and $40 \%$ similarity to ZmExo1, 3 and 4, respectively).

Most of the sequences for endochitinase genes (24 of 27) and all of the exochitinase genes were present, at least in partial form, in EST libraries. The sequences of 22 of the endochitinase genes and all of the exochitinase genes were also found in genomic libraries (Table 1). Of the 24 endo genes expressed in ESTs, 17 were obtained from tissue exposed to biotic or abiotic stresses (Table 2). However, all of them were also expressed in plant tissues presumably not under stress, and especially in various types of reproductive tissues, meristems or seeds.

The phylogenetic relationships between the endochitinase and exochitinase genes are given in Figs. 1, 2 respectively. Within endochitinases PR3 classes I and II (family 19), substantial diversity occurs in the signal peptide region, the hinge region and the $\mathrm{C}$-terminal extension region. The catalytic region consists of two regions that are highly conserved and a less conserved central region (Fig. 3). The class IV endochitinases are highly conserved over most of their lengths, with the exception of a short hinge region (Fig. 3). Chitinase class II (also family 19) genes are the smallest of the chitinolytic enzymes and are quite similar to each other (Fig. 4). Class III of PR8 (family 18) can be subdivided into IIIA, which includes signal peptides, and IIIB, which lack this feature (Fig. 5a, b).

Genes expressed in response to root colonization by $T$. harzianum

Proteins isolated from maize were subjected to SDS-PAGE and bands with activity were subjected to LC/MS/MS after 
Table 1 Endochitinases and exochitinases of maize genes

\begin{tabular}{|c|c|c|c|c|c|c|}
\hline Name & Accession & Unigene & HTGS & $\mathrm{Chr}$ & $\mathrm{Mw}(\mathrm{kDa})$ & $\mathrm{pI}$ \\
\hline Chil24175 & 78021586 & $\mathrm{Zm} .24175$ & No match & Unknown & 35.302 & 7.37 \\
\hline ChiI93771 & 168444 & Zm.93771 & AC208338.1 & 6 & 33.526 & 4.88 \\
\hline ChiI1 1654 ${ }^{\mathrm{a}}$ & & Zm.11654 \& Zm.97305 & AC208338.1 & 6 & 38.955 & 4.87 \\
\hline Chil201 ${ }^{\mathrm{b}}$ & 293884 & $\mathrm{Zm} .201$ & No match & Unknown & 37.483 & 4.84 \\
\hline ChiI1765 ${ }^{\mathrm{b}}$ & 21210553 & $\mathrm{Zm} .1765$ & AC208416.1 & 5 & 30.057 & 5.10 \\
\hline ChiI3726 & 21209068 & Zm.3726 & AC203444.2 & 7 & 34.775 & 8.49 \\
\hline ChiII $10257^{\mathrm{a}}$ & & Zm.10257 & AC210717.1 & 1 & 27.75 & 4.74 \\
\hline ChiII67336 & 21206817 & $\mathrm{Zm} .67336$ & AC195193.2 & 1 & 27.86 & 8.69 \\
\hline ChiII96529a & & Zm.96529 & AC195193.2 & 1 & 28.40 & 8.99 \\
\hline ChiIV $^{\mathrm{b}}$ & 21208678 & Zm.95681 & AC197114.3 & 5 & 29.231 & 5.32 \\
\hline ChiIVA & 48093225 & Zm87295 & AC186025.4 & 2 & 29.552 & 8.43 \\
\hline ChiIVB & 48093317 & Zm.92797 & No match & Unknown & 29.448 & 8.89 \\
\hline ChiIVC $^{\mathrm{a}}$ & No match & No match & AC186025.4 & 2 & 29.192 & 7.86 \\
\hline ChiIVD $^{\mathrm{a}}$ & & $\mathrm{Zm} .87300$ & AC200107.2 & 10 & 29.644 & 9.79 \\
\hline ChiII-PR4 & 21207932 & $\mathrm{Zm} .2227$ & AC204382.2 & 4 & 16.028 & 6.95 \\
\hline ChiII-PR4b ${ }^{a}$ & & $\mathrm{Zm} .2227$ & AC204382.2 & 4 & 15.15 & 6.50 \\
\hline ChiII-drp & 559533 & $\mathrm{Zm} .38616$ & AC204382.2 & 4 & 15.911 & 8.97 \\
\hline ChiII-drpb $^{a}$ & & No match & AC204382.2 & 4 & & \\
\hline ChiIIIc $^{\mathrm{a}}$ & & No match & AC202541.1 & 3 & & \\
\hline ChiIII2139a & & $\mathrm{Zm} .84867$ & AC191027.2 & 7 & 33.714 & 7.11 \\
\hline ChiIII28325 & & $\mathrm{Zm} .8325$ & No match & Unknown & 31.352 & 5.14 \\
\hline ChiIII24099a & & Zm.24099 & AC193625.2 & 4 & 30.368 & 9.16 \\
\hline ChiIII21556 ${ }^{\mathrm{a}}$ & & Zm.21556 & AC191027.2 & 7 & 32.995 & 9.21 \\
\hline ChiIII9675 & & Zm.9675 & No match & Unknown & 31.278 & 4.64 \\
\hline ChiIII9615 ${ }^{\mathrm{a}}$ & & $\mathrm{Zm} .9615$ & AC206270.1 & 4 & 32.536 & 8.69 \\
\hline ChiIII-PRm3 & 1839588 & Zm.95692 & AC185489.3 & 3 & 30.118 & 4.10 \\
\hline ChiIII32462 ${ }^{\mathrm{a}}$ & & $\mathrm{Zm} .32462$ & AC199067.2 & 3 & 32.399 & 9.12 \\
\hline $\mathrm{ZmExo1}^{\mathrm{b}}$ & 21209897 & Zm.1436 & AC203221.2 & Unknown & 61.23 & 5.88 \\
\hline $\mathrm{ZmExo} 2^{\mathrm{b}}$ & 54653093 & Zm.15748 & AC202990.2 & 1 & 64.99 & 5.95 \\
\hline $\mathrm{ZmExo}^{\mathrm{b}}$ & 21209061 & $\mathrm{Zm} .3467$ & AC207734.1 & 6 & 55.20 & 5.77 \\
\hline $\mathrm{ZmExo} 4^{\mathrm{b}}$ & 21216992 & $\mathrm{Zm} .12507$ & AC195356.2 & 8 & 55.87 & 5.50 \\
\hline
\end{tabular}

Columns indicate accession of mRNA, Unigene no. and accession of High Throughput Genomic Sequences (HTGS) databases and chromosome location, where available. The calculated $\mathrm{Mw}$ and $\mathrm{pI}$ are also listed

a Genes that were built and modeled in this study

b Partial cDNA was available; we completed the gene sequence

digestion with trypsin. Five endochitinases were detected only in shoots; one exochitinase (ZmExo2) and another endochitinase (ChiIII9615) were detected in both shoots and roots (Fig. 6; Table 3). The enzymes differed in shoots and roots and in plants grown in the presence or absence of T. harzianum strain T22. A mixture of substrates was used for the in-gel activity assay, since we wished to detect all proteins with chitinolytic activities in these tests. Therefore, no information could be obtained regarding enzyme activity type or synthetic substrate specificity. However, of the identified proteins, all of the enzymes detected were of the size predicted (minor differences from predicted $\mathrm{Mw}$ could be attributed to post translational modifications) except for proteins in both shoots and roots that were $95 \mathrm{kDa}$ in size (Fig. 6). These were larger than any of the masses of the chitinolytic enzymes identified in this study. However, when they were treated at $100^{\circ} \mathrm{C}$, the $95 \mathrm{kDa}$ proteins disappeared and were replaced by bands with smaller masses. These large proteins appear to be heterodimers between ZmExo2 and ChiIVA (control shoots), ChilII9675 (T22 shoots) or ChiIII9615 (control roots) (Table 3). A full description of these heterodimers and their biological activities is described elsewhere (Shoresh and Harman 2008). 
Table 2 Chitinase gene expression in maize

\begin{tabular}{|c|c|c|}
\hline Name & Stress related treatments & Tissue location \\
\hline ChiI24175 & Salt stressed roots (low) & Meristem, root \\
\hline ChiI93771 & F.g. inoculated corn eartip (high) & Ear, leaf \\
\hline ChiI11654 & Roots-low water potential (low) & Meristem \\
\hline ChiI201 & & Pollen \\
\hline Chil1765 & & Pollen \\
\hline ChiI3726 & & Ear, embryo, endosperm, meristem, root \\
\hline ChiII10257 & & Mixed tissues \\
\hline ChilI67336 & F.g. inoculated corn eartip (low) & Ear, glume, pericarp, root, silk \\
\hline Chill96529 & Roots-low water potential (low) & Glume, root \\
\hline ChiII-PR4 & $\begin{array}{l}\text { F.g. inoculated corn eartip (high) and silk } \\
\text { (high), roots-low water potential (low) }\end{array}$ & Ear, glume, meristem, ovary, silk \\
\hline ChiII-PR4b & $\begin{array}{l}\text { F.g. inoculated corn eartip (high) and silk } \\
\text { (high), roots-low water potential (low) }\end{array}$ & Ear, glume, meristem, ovary, silk \\
\hline ChilI-drp & $\begin{array}{l}\text { F.g. inoculated corn eartip (high) and silk } \\
\text { (high), roots-low water potential (moderate) }\end{array}$ & Ear, glume, root, silk \\
\hline ChillI2139 & $\begin{array}{l}\text { Roots-low water potential (low); salt stressed } \\
\text { roots (moderate); silk infected with F.g. (high) }\end{array}$ & Endosperm, glume, ovary, root, silk \\
\hline ChiIII28325 & Roots-low water potential (low) & Root \\
\hline ChiIII24099 & F.g. inoculated corn eartip (high) & Ear, leaf, ovary, root \\
\hline ChiIII21556 & Roots-low water potential (low) & Meristem \\
\hline ChillI9675 & & Ovary \\
\hline ChillI9615 & & Endosperm, root \\
\hline ChiIII-PRm3 & Leaves infected with X.o. (high); roots-low water potential (low) & Glume, leaf \\
\hline ChiIII32462 & F.g. inoculated silk (moderate) & Silk \\
\hline ChiIV & & Mixed tissues \\
\hline ChiIVA & F.g. inoculated corn eartip (moderate) & $\begin{array}{l}\text { Aleurone, ear, embryo, endosperm, } \\
\text { glume, ovary }\end{array}$ \\
\hline ChilvB & F.g. inoculated corn eartip (high); silk infected with Fusarium (high) & $\begin{array}{l}\text { Aleurone, ear, endosperm, glume, } \\
\text { meristem, ovary, pollen, silk }\end{array}$ \\
\hline ChiIVD & F.g. inoculated corn eartip and silk (low) & Ear, embryo, endosperm, glume, silk \\
\hline ZmExo1 & Roots-low water potential (low) & Silk, glume, root \\
\hline ZmExo2 & & Endosperm \\
\hline ZmExo3 & & $\begin{array}{l}\text { Tassel, ovary, root, embryo, } \\
\text { endosperm, meristem }\end{array}$ \\
\hline ZmExo4 & & Root \\
\hline
\end{tabular}

The information for stress-related treatments was extracted from EST libraries 14454, 14455, 15083, 15076, 15084, 8918, 8920, 10952, 12115. F.g. Fusarium graminearum, X.o. Xanthomonas oryzae. Genes for which there was no information were excluded from this table. Intensity of the stress applied to the plants is indicated in parentheses

\section{Discussion}

We believe that this study comprises the most comprehensive description of genes encoding chitinolytic enzymes in a specific plant. Recently, a similar paper on rice (Nakazaki et al. 2006) was published but it considered only the PR3 family 19 genes. A survey of Arabidopsis chitinases did not include the genes of PR4 endochitinases or the exo enzymes (Passarinho and de Vries 2002). Of the 27 maize endochitinases described here only seven were described earlier: ChiI93771 and Chil201 (Wu et al. 1994), ChiIVA and ChiIVB (Huynh et al. 1992), ChiII-PR4 (Bravo et al. 2003), ChiII-drp (Chevalier et al. 1995), and ChiIII-PRm3 (Didierjean et al. 1996). The sequences for the other genes were present in EST and genomic databases, but were heretofore not studied. Since not all the maize genome sequences were available at the end of this study it is possible that other maize genes that encode chitinolytic enzymes exist. We found cases where a Unigene presumed to contain sequences of one chitinase actually contained sequences of two related genes (as in the case of ChilIPR4). 
Fig. 1 Phylogenetic tree of maize endochitinase proteins. All sequences here are full proteins (contig assembly and gene modeling were done when needed)

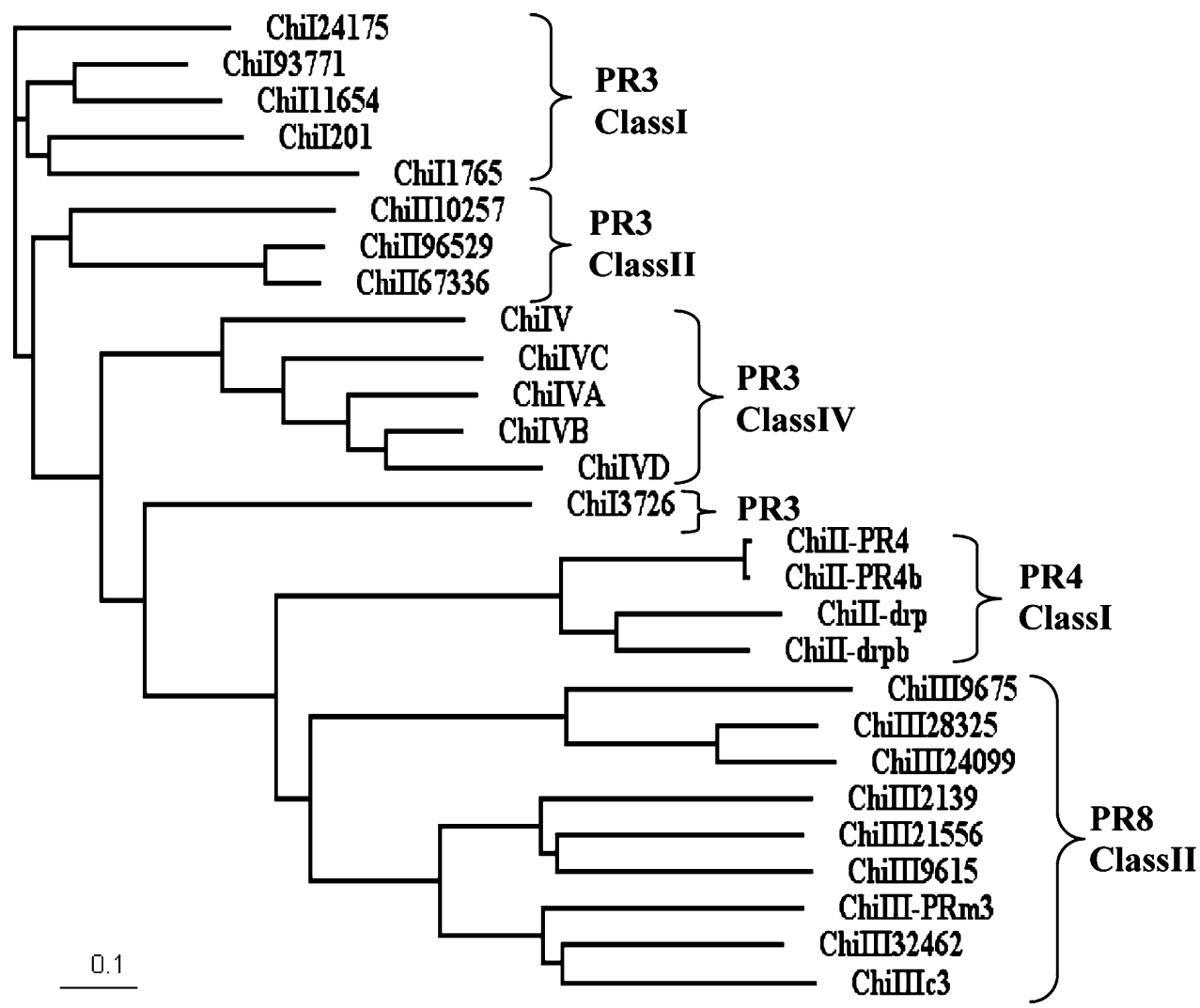

Class I endochitinases are composed of a signal peptide in their $\mathrm{N}$ terminus followed by a chitin binding domain that harbors the chitin binding signature PS00026 (ProSite). Class I enzymes belong to glycosyl-hydrolase family 19 and possess the chitinase signatures PS00773 and PS00774 (ProSite). The chitinase catalytic domain is preceded by a variable hinge region rich in proline residues. This domain is also followed by a short C-terminal extension. The C-terminal extension in class I proteins has been postulated to be involved in vacuolar targeting (Neuhaus et al. 1991b). Endochitinases ChiI24175, ChiI93771, ChiI11654 and ChiI201 have all the features of typical class I chitinolytic enzymes and possess all of the essential and important residues for catalytic activity, indicating they are active chitinases. Although InterProScan identified ChiI1765 as a member of the glycosyl-hydrolase family 19 , it has a deletion encompassing important residues for catalytic activity and its chitinase signatures are incomplete, indicating that its chitinase activity may be compromised. It does not exclude, however, other functions for the protein since it is expressed (ESTs were found). ChiI3726 was fairly distant to other class I endochitinases (Fig. 1). It too lacks typical chitinase signatures. Nevertheless this chitinase is expressed indicating it has some functionality. Chitinases ChiII67336, ChilI96529 and ChiII10257 have the catalytic domain of the same type as the class I chitinases but with a 16 amino-acid deletion that encompasses loop 2 of the 


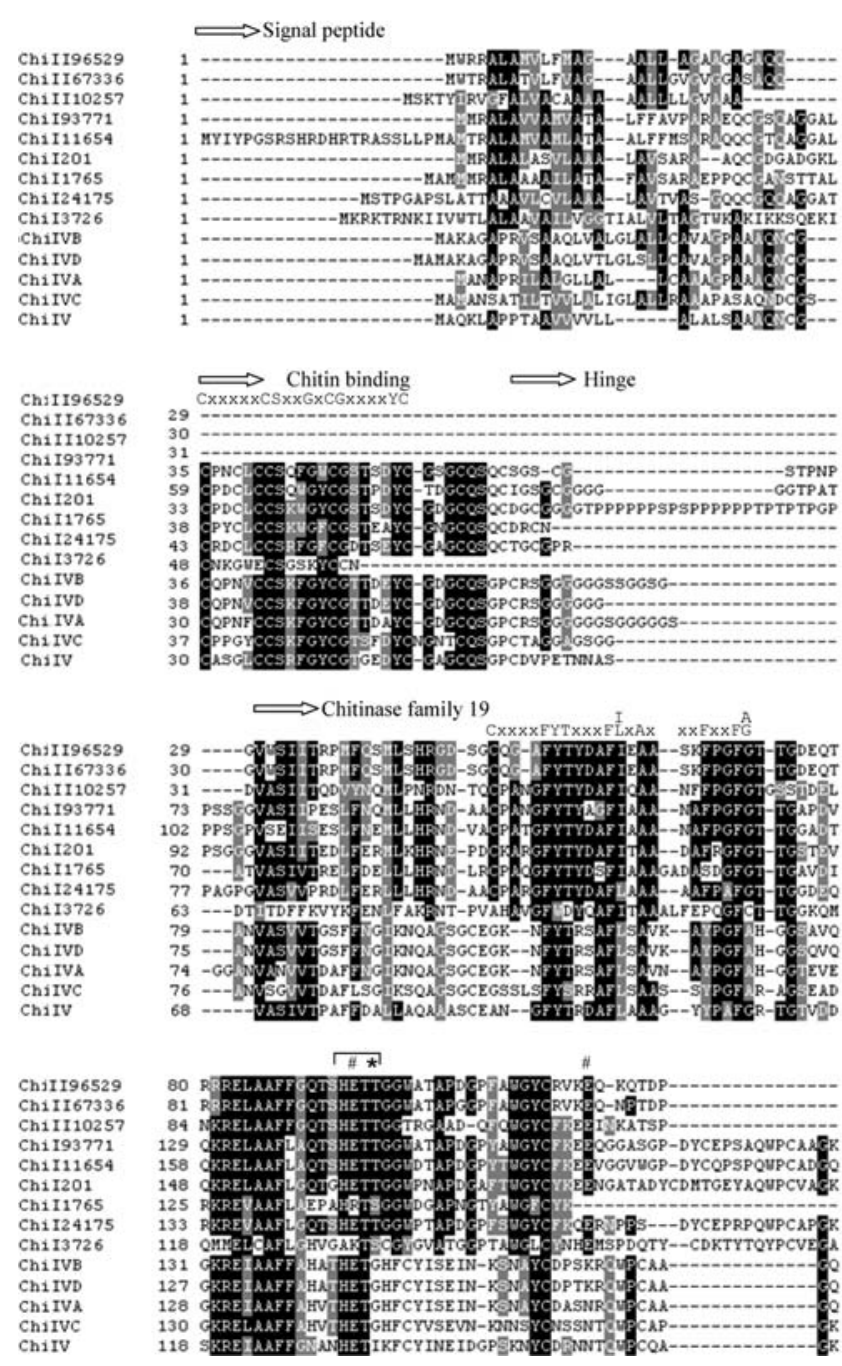

Fig. 3 Structural domains of maize PR3 endochitinases. Black and shaded backgrounds indicate amino acids that are identical or similar, respectively. Dashes indicate no residue present at that position. Protein domains were identified using InterProScan. The beginning of each domain is indicated by an arrow with the name of the domain following it (each domain ends just before the arrow for the next domain). The chitinase family 19 (pfam00182) was identified and its signatures (PS00773 and PS00774) are indicated as letters above the alignment. The chitin binding domain signature (PS00026) is also indicated by letters above the alignment and is followed by the hinge region. The signal peptide was identified, which presumably directs the proteins

catalytic domain. This is characteristic to class II as defined by Nakazaki et al. (2006) or class IIb as defined by Neuhaus (1999). They all lack the chitin-binding domain, as well as the accompanying hinge region, similar to the PR3 class II chitinases in rice (Nakazaki et al. 2006).

The main structure of class IV endochitinases is very similar to that of class I enzymes (Fig. 3) and they share sequence similarity. However, several short deletions in the catalytic domain differentiate class IV chitinases from class I chitinases (Tiffin 2004) (Fig. 3). This was also observed for class IV chitinases from Arabidopsis and rice (Passarinho

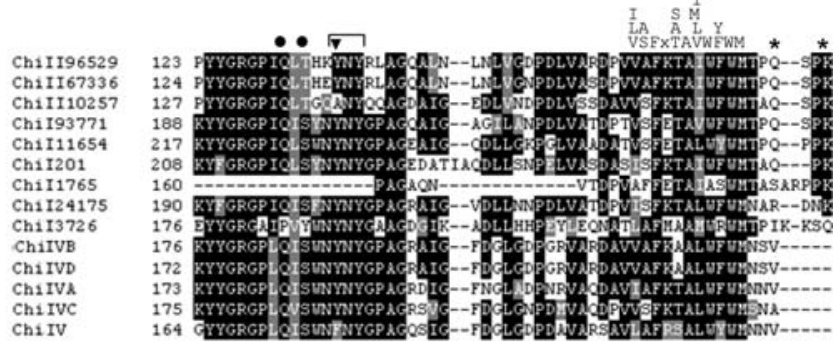

Chir1 196529

Chi1167336

Chi1110257

Chi111654

Ch11201

Chil1765

Ch1 124175

Chi1372

Chirv

ChirvD

Chirve

Chirve

Chir196529
Ch11167336
Chir110257
Chi193771
Chir11654
Chi1201
Chir1765
Ch1124175
Chi13726
ChirVB
ChirVD
ChirVl
Chirve
ChirV
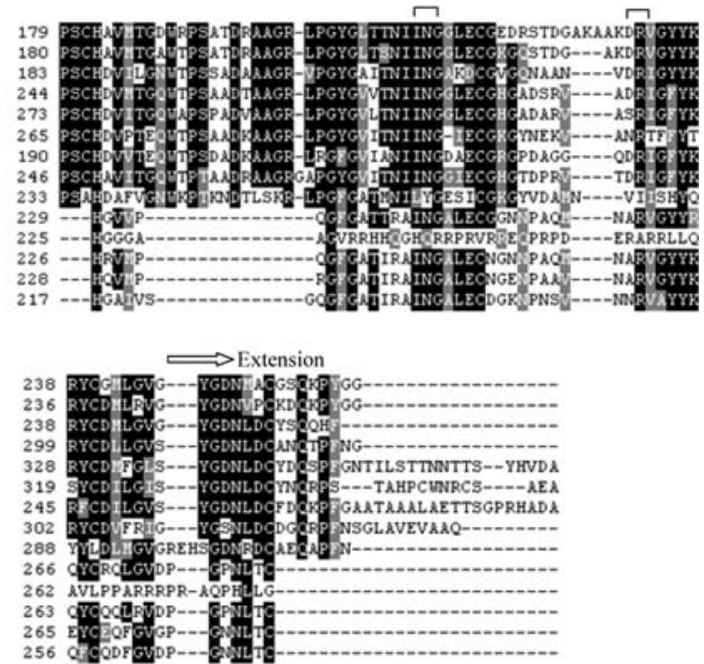

outside the cell. The symbol \# marks residues that are essential and closed circles mark residues that are important for catalytic activity in class I chitinases (Garcia-Casado et al. 1998). The symbol $\cap$ represents residues that are important for substrate binding (Garcia-Casado et al. 1998; Verburg et al. 1992, 1993). The tyrosine residue indicated by triangle is essential for substrate binding but not for the catalysis (Verburg et al. 1992, 1993). Asterisks represent positions that are important for substrate binding but are consistently different between class I and class IV chitinases. This appears to be the same in Arabidopsis (Passarinho and de Vries 2002) and most likely reflects a classrelated difference in substrate specificity

and de Vries 2002; Nakazaki et al. 2006). All of the maize class IV enzymes described in this work are composed of a signal peptide followed by a chitin-binding domain that harbors the chitin binding signature PS00026 (ProSite). Like class I chitinases, class IV chitinases belong to the glycosyl-hydrolase family 19 and possess the chitinase signatures PS00773 and PS00774 (ProSite). The chitinase domain is preceded by a variable hinge region rich in glycine or proline/glycine residues. Unlike class I endochitinases, the class IV endochitinases lack a short C-terminal extension. All class IV maize chitinases possess all structural features 


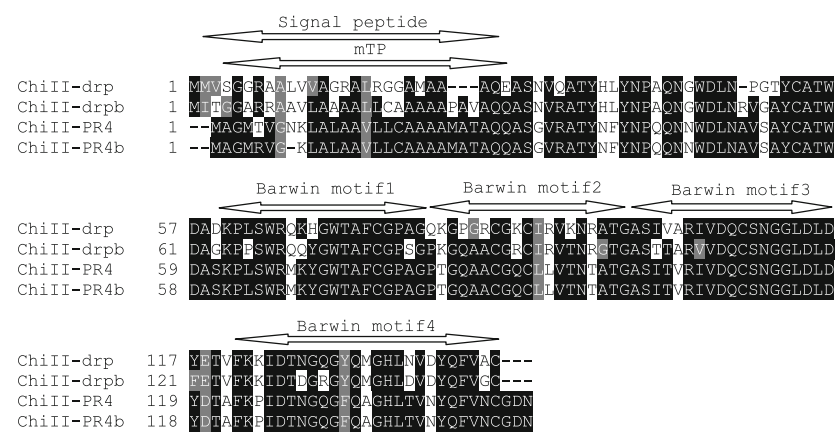

Fig. 4 Structural domains of maize class II endochitinases. Black and shaded backgrounds indicate amino acids that are identical or similar, respectively. Dashes indicate no residue present at that position. Protein domains were identified using InterProScan. The Barwin family signatures (PR00602) are indicated by arrows. Arrows indicate the signal peptide, which presumably direct the PR4 and PR4b proteins outside the cell, and a mitochondrial targeting peptide (mTP) for drp and drpb proteins

important for their enzymatic activity indicating they are active chitinases. The study of Arabidopsis chitinases indicated that several residues appeared to be important for substrate binding but were consistently different between class I and class IV enzymes (Passarinho and de Vries 2002). For example, a conserved tyrosine residue, which was demonstrated to be important for substrate binding in class I proteins (Verburg et al. 1993), is replaced in an active Arabidopsis class IV chitinase by phenylalanine. Similar differences were observed in maize chitinases (Fig. 3). These differences most likely reflect a class-related difference in substrate specificity.

PR4-class II endochitinases also belong to glycosylhydrolase family 19 and specifically harbor the Barwin family signature (PR00602). They lack a chitin-binding domain that is present in class I and class IV (Fig. 4). They all have a signal peptide; however, while ChiII-PR4 and $\mathrm{PR} 4 \mathrm{~b}$ are predicted to be transferred into chloroplasts, ChiII-drp and drpb are predicted to be targeted to mitochondria (Fig. 4).

We were able to identify nine maize chitinases with glycosyl-hydrolase family 18 signatures. In both Arabidopsis and rice genomes the glycosyl-hydrolase family 18 divides into two main groups, class III and class V chitinases (Passarinho and de Vries 2002; Yokoyama and Nishitani 2004). However, phylogenetic analysis of the maize family 18 proteins demonstrate that they all cluster with chitinase III and not with the class $\mathrm{V}$ chitinases of Arabidopsis (Fig. 7). Class IIIa maize endochitinases contain a signal peptide, while class IIIb lack this feature. In addition, the C-terminal extension is longer in class IIIb than class IIIa chitinases (Fig. 5a, b). Genes encoding class IIIb endochitinases are found only in monocots (Suzukawa et al. 2003; Park et al. 2004).

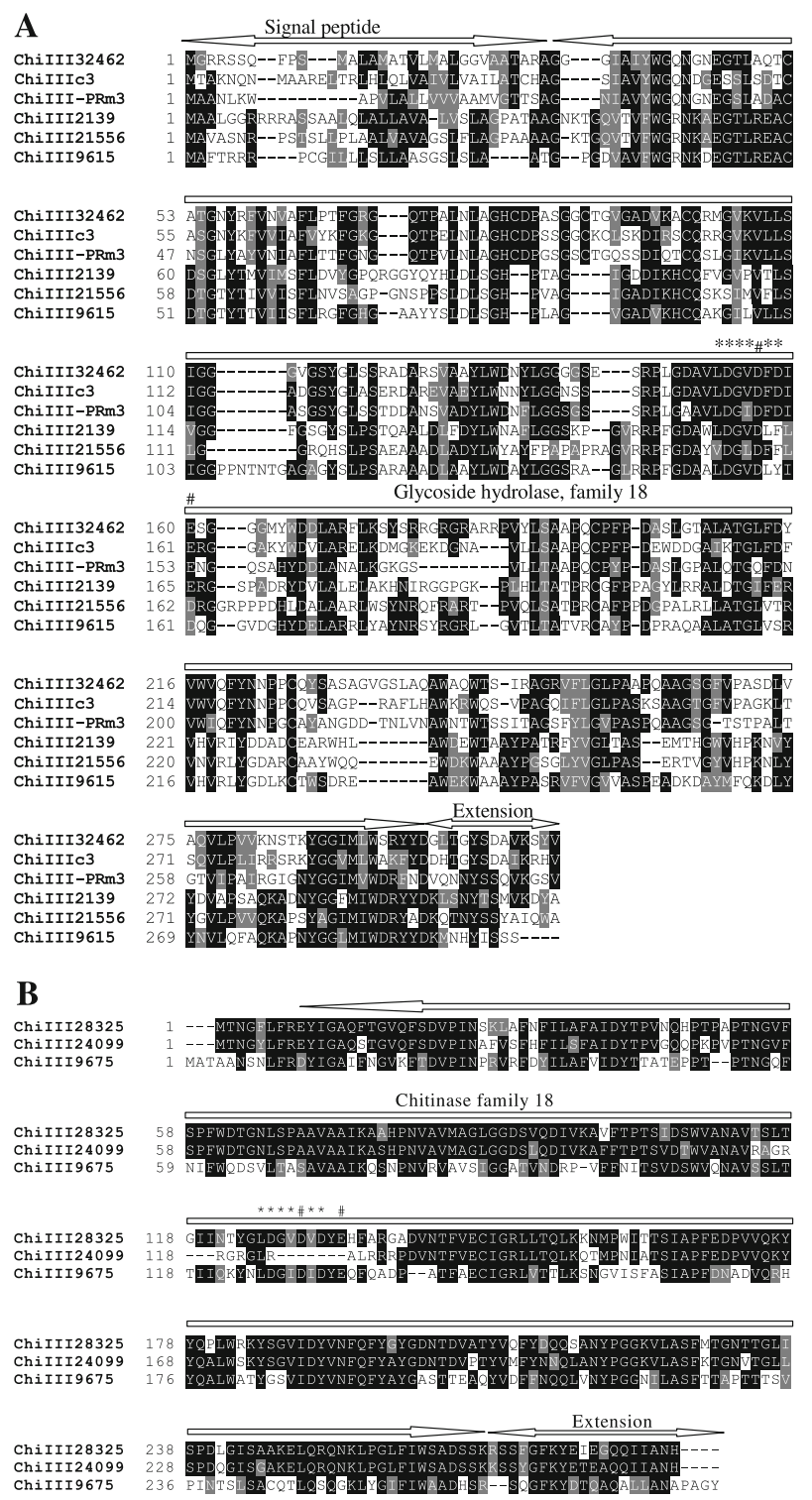

Fig. 5 Structural domains of maize class IIIa (a) and class IIIb (b) endochitinases. Black and shaded backgrounds indicate amino acids that are identical or similar, respectively. Dashes indicate no residue present at that position. Unigenes 9615, 2139, 21556, 32462, 28325 , 24099, and 9675 were assembled into complete proteins from both EST and genomic sequences. Protein domains were identified using InterProScan. The Glycoside hydrolase family 18 (pfam00704) is indicated by an arrow with the active site (PS01095) indicated by the symbols \# and *, which mark residues that are essential or important for catalytic activity, respectively (Suzukawa et al. 2003; Watanabe et al. 1993). An arrow indicates the signal peptide, which presumably directs the proteins outside the cell. A C-terminal extension is also indicated

In two class IIIa endochitinases, ChiIII21556 and ChiIII9615, an essential glutamic acid at the active site is substituted by aspartic acid. When an analogous glutamic acid was substituted by aspartic acid in the class III chitinase A1 of Bacillus circulans, the catalytic activity of the 


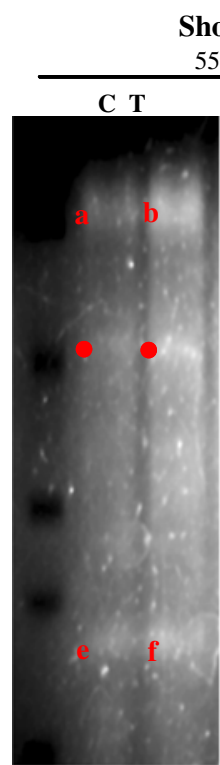

$30 \mathrm{~min}$ incubation

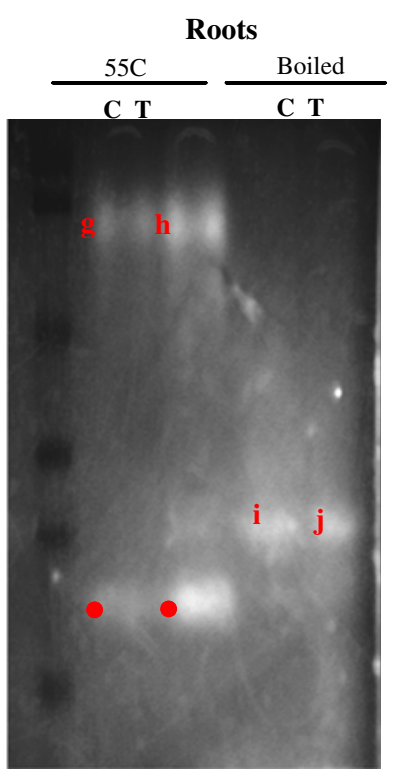

30min incubation

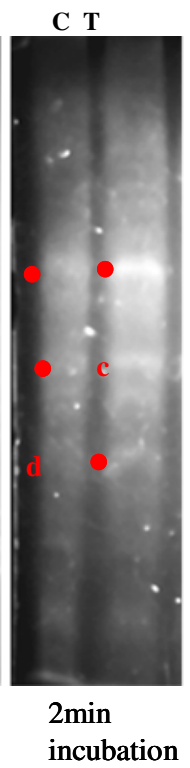

Fig. 6 Comparison of chitinase activity banding patterns of proteins extracts from control plants $(C)$ and Trichoderma-inoculated $(T)$ plants. As described in the materials and methods, polyacrylamide gels with equal loading in each lane were removed from the glass plates following electrophoresis, subjected to various renaturation washes, and stained for chitinase activities using methylumbelliferyl substrates that were dissolved in $100 \mathrm{mM}$ acetate buffer ( $\mathrm{pH} \mathrm{5.0)}$ ) containing $1 \%$ low melting agarose. Chitinase activity bands from shoots are shown in shoots and roots. Activity bands started to appear as early as after 2 min of incubation. Molecular size markers: 106, 93, 52, 32, 28, and $18 \mathrm{kDa}$. These experiments were repeated three times with proteins extracted from three independent experiments. Letters next to protein band mass are the marks of the relevant bands in Table 3. Red dots represent activity bands that were not identified

enzyme was abolished (Watanabe et al. 1993). However, one of the activity bands identified from the roots was identified as ChiIII9615 indicating it is an active endochitinase. In fact, ChiIII9615 has a Glu residue ten amino acids downstream of the Glu residue found in the other class IIIa endochitinases. This Glu residue is also preceded by two Asp residues, hence it possesses all of the residues crucial for catalytic activity. ChilII24099 (class IIIb) completely lacks the active site. However, this gene was composed from EST sequences indicating that it is expressed and hence most likely encodes a functional protein. InterProScan identified a $2 \mathrm{~S}$ globulin signature in ChiIII24099 (PR00551), which is a child-domain of family 18. Globulins are a family of proteins of different size and structural organization that share several properties (including similar amino acid composition) and function as storage proteins. The globulins are generally classified with respect to their molecular mass as $2 \mathrm{~S}, 7 \mathrm{~S}$ (vicilin) or $11 \mathrm{~S}$ (legumin). Narbonin, a storage protein found in seeds of Vicia narbonensis (Hennig et al. 1992; Nong et al. 1995), belongs to the
Table 3 Chitinolytic enzymes detected in seven-day-old maize seedlings in the presence or absence of $T$. harzianum strain T22 following separation of proteins on SDS-PAGE and use of LC/MS/MS to identify the proteins in each band

\begin{tabular}{lllll}
\hline $\begin{array}{l}\text { Protein band } \\
\text { mass }(\mathrm{kDa})\end{array}$ & Tissue & Treatment & $\begin{array}{l}\text { Enzyme(s) } \\
\text { identified }\end{array}$ & $\begin{array}{l}\text { Percentage } \\
\text { confidence }\end{array}$ \\
\hline $95^{\mathrm{a}}$ & Shoot & Untreated & $\begin{array}{l}\text { ZmExo2 } \\
\text { ChiIVA }\end{array}$ & 96 \\
& & & 99 \\
$95^{\mathrm{b}}$ & Shoot & T22 & $\begin{array}{l}\text { ZmExo2 } \\
\text { ChiIII9675 }\end{array}$ & 99 \\
& & & ChiI11654 & 99 \\
$43^{\mathrm{c}}$ & Shoot & T22 & ChilVB & 99 \\
$30^{\mathrm{d}}$ & Shoot & Untreated & ChiI67336 & 99 \\
$25^{\mathrm{e}}$ & Shoot & Untreated & ChiI67336 & 99 \\
$25^{\mathrm{f}}$ & Shoot & T22 & ZmExo2 & 96 \\
$95^{\mathrm{g}}$ & Root & Untreated & ChiIII9615 & 98 \\
& & & ZmExo2 & 90 \\
$95^{\mathrm{h}}$ & Root & T22 & ChiIII9615 & 97 \\
$30^{\mathrm{i}}$ & Root & Untreated & ChiIII9615 & 99 \\
$30^{\mathrm{j}}$ & Root & T22 & \\
\hline
\end{tabular}

The percentage confidence indicated the level of confidence in the identification of each band based on LC/MS/MS data. Superscript letters next to protein band mass are the marks of the relevant bands in Fig.6

smaller $2 \mathrm{~S}$ globulins. In concavalin $\mathrm{B}$, another close relative of family 18 chitinases, a glutamic acid residue is replaced by glutamine resulting in the loss of catalytic activity (Hennig et al. 1995). This protein, however, which is present in the seeds of Canavalia ensiformis, has retained its carbohydrate binding function (Hennig et al. 1995). It could be therefore postulated that inactive maize chitinase proteins may function similarly as carbohydrate binding proteins.

In the past only three different exochitinase activities were detected in maize (Oikawa et al. 2003). However, four different genes exist in the maize genome. The four maize exochitinase genes were compared to rice sequences and five Unigenes were identified: Os.9285, Os.51024, Os.7435, Os.26716, and Os.23475. Comparison of Os.9285 and Os.51024 demonstrated that these are alternative spliced forms (alternative first exon). Both of these genes are homologues of the maize ZmExo1. By BLAST analysis we found that this alternative exon is present in the maize genome. The protein sequence, however, does not differ between the two forms. Os.7435 is homologous to maize ZmExo2. The gene product of Os. 23475 highly resembles the gene product of Os.26716 (83\% similarity). Both Os.23475 and Os.26716 are similar to maize ZmExo3 and ZmExo4 (90 and 81\% similarity, respectively) and may have evolved from a common ancestor before the split of dicot and monocot plants (Fig. 2).

In some cases, there are duplicates of some of the genes closely spaced on a single chromosome. In the case of Chill 
Fig. 7 A comparison between class III maize endochitinases and class III and V endochitinases of Arabidopsis and rice. It is clear that all family 18 maize proteins cluster with the class III chitinases and not with class V. A tulip class IIIb chitinase, which was structurally studied, was also added

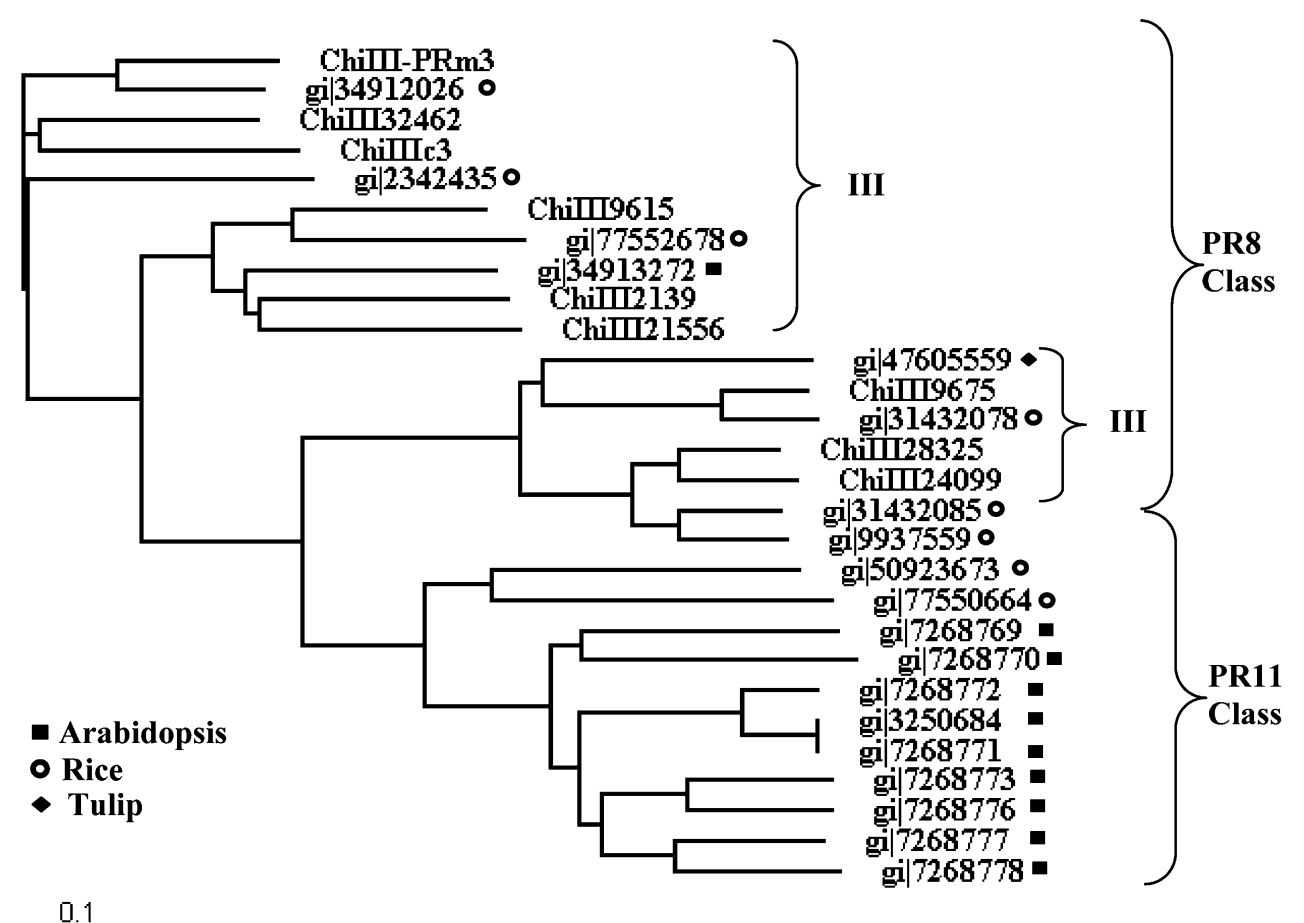

0.1

genes located on chromosome 4, this is likely to have resulted from activity of transposon sequences located nearby (Fig. 8).

Many of the genes were derived from sequences found in tissues exposed to biotic or abiotic stresses, which would be expected since they have long been considered as PR proteins (Table 2). In other studies ChiI93771, ChiI201, ChiIVA, ChiIVB and ChiII-PR4 were shown to be expressed in response to pathogens (Huynh et al. 1992; Wu et al. 1994; Bravo et al. 2003). Altogether this demonstrates that different chitinases function in stress response. However, they were also very commonly found in tissues not exposed to such stresses, especially reproductive structures, meristems and seed components such as aleurone and endosperm tissues (Table 2). This suggests a role for these enzymes in functions other than defense against pathogens or stresses, but these functions are not clearly known.

In experimental work, expression of a number of chitinolytic enzymes were detected in plants not inoculated with T. harzianum and there were differences in banding patterns between shoots and roots. Root colonization by T. harzianum strongly influenced the chitinolytic enzymes that were detected in both roots and shoots even though $T$. harzianum was present only on roots; it is known to induce systemic resistance to plant diseases (Harman et al. 2004b). We were surprised to observe in both roots and shoots an activity band of about $95 \mathrm{kDa}$, which is larger than any chitinase that we identified. This band appears to be a heterodimer between ZmExo2 and any of several endochitinases. The specific endochitinase associated with the ZmExo2 differed depending on whether it was expressed in shoots or roots and whether or not T. harzianum was present. We were intrigued by this observation since mixtures of exo and endo enzymes from microbial sources are much more strongly antifungal than a similar concentration of either an endo or an exo alone; the antifungal activity between the two classes of enzymes is synergistic (Lorito 1998). Therefore, the presence of exo/endo heterodimers was intriguing from the standpoint of plant protection. In related work, these heterodimers were purified and their activity against Penicillium digitatum was very high; the $\mathrm{IC}_{50}$ was $1.4 \mathrm{ppm}$ for the dimer from shoots of Trichoderma-treated plants vs. the $\mathrm{IC}_{50}$ of $3.7 \mathrm{ppm}$ for the dimer from control plants; which are lower values than for any single enzyme from microbial sources of which we are aware (Shoresh and

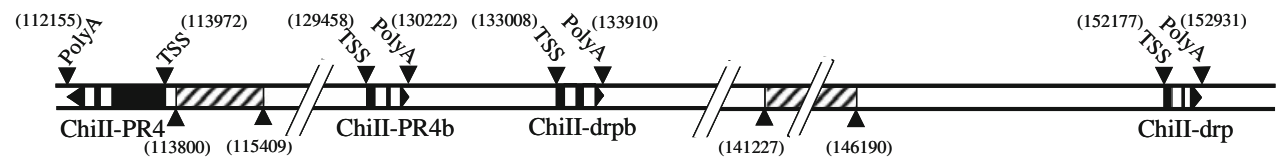

Fig. 8 Genomic organization of the PR4 endochitinase genes on chromosome 4. TSS indicates the transcriptional start site; PolyA indicates the polyadenylation site. Arrowheads point to the positions (in brack- ets) of the sequence found in accession 157152486. Black arrows within the box represent the gene, white regions within are the coding sequences. Hatched boxes represent transposon sequences 
Harman 2008). This unexpected result provides interesting new information on the mechanisms of resistance in plants and suggests that such enzymes might be powerful tools in increasing resistance of plants to diseases.

Acknowledgments This research was supported in part by the US-Israel Agricultural Research and Development fund (BARD) grant US-3507-04 R and by Advanced Biological Marketing (Van Wert, $\mathrm{OH})$. We thank Kristen Ondik for review and comments on the paper.

\section{References}

Baldan B, Guzzo F, Filippini F, Gasparian M, LoSchiavo F, Vitale A, de Vries SC, Mariani P, Terzi M (1997) The secretory nature of the lesion of carrot cell variant ts 11 , rescuable by endochitinase. Planta 203:381-389

Berger S, Menudier A, Julien R, Karamanos Y (1995) Do de- $N$-glycosylation enzymes have an important role in plant cells? Biochimie 77:751-760

Bolar JP, Norelli JL, Wong K-W, Hayes CK, Harman GE, Aldwinckle HS (2000) Expression of endochitinase from Trichoderma harzianum in transgenic apple increases resistance to apple scab and reduces vigor. Phytopathology 90:72-77

Bolar JP, Norelli JL, Harman GE, Brown SK, Aldwinckle HS (2001) Synergistic activity of endochitinase and exochitinase from Trichoderma atroviride (T. harzianum) against the pathogenic fungus (Venturia inaequalis) in transgenic apple plants. Trans Res 10:533-543

Bravo JM, Campo S, Murillo I, Coca M, San Segundo B (2003) Fungus- and wound-induced accumulation of mRNA containing a class II chitinase of the pathogenesis-related protein 4 (PR-4) family of maize. Plant Mol Biol 52:745-759

Chevalier C, Bourgeois E, Pradet A, Raymond P (1995) Molecular cloning and characterization of 6 cDNAs expressed during glucose starvation in excised maize (Zea mays L.) root tips. Plant Mol Biol 28:473-485

Choi SY, Gross KC (1994) N-Acetyl-beta-D-glucosaminidase from "Golden Delicious" apples. Phytochemistry 36:1-6

Didierjean L, Frendo P, Nasser W, Genot G, Marivet J, Burkard G (1996) Heavy-metal-responsive genes in maize: identification and comparison of their expression upon various forms of abiotic stress. Planta 199:1-8

Dyachok JV, Wiweger M, Kenne L, von Arnold S (2002) Endogenous nod-factor-like signal molecules promote early somatic embryo development in Norway spruce. Plant Physiol 128:523-533

Garcia-Casado G, Collada C, Allona I, Casado R, Pacios LF, Aragoncillo C, Gomez L (1998) Site-directed mutagenesis of active site residues in a class I endochitinase from chestnut seeds. Glycobiology 8:1021-1028

Geurts R, Franssen H (1996) Signal transduction in Rhizobiuminduced nodule formation. Plant Physiol 112:447-453

Harman GE, Custis D (2006) Formulations of viable microorganisms and their method of use. US Patent WO 2007030557

Harman GE, Shoresh M (2007) The mechanisms and applications of opportunistic plant symbionts. In: Vurro M, Gressel J (eds) Novel biotechnologies for biocontrol agent enhancement and management, Springer, Amsterdam, pp 131-153

Harman GE, Howell CR, Viterbo A, Chet I, Lorito M (2004a) Trichoderma species-opportunistic, avirulent plant symbionts. Nat Rev Microbiol 2:43-56

Harman GE, Petzoldt R, Comis A, Chen J (2004b) Interactions between Trichoderma harzianum strain T22 and maize inbred line Mo17 and effects of these interactions on diseases caused by
Pythium ultimum and Colletotrichum graminicola. Phytopathology $94: 147-153$

Hennig M, Schlesier B, Dauter Z, Pfeffer S, Betzel C, Hohne WE, Wilson KS (1992) A TIM barrel protein without enzymatic activity? Crystal structure of narbonin at 1.8-angstrom resolution. FEBS Lett 306:80-84

Hennig M, Pfeffer-Hennig S, Dauter Z, Wilson KS, Schlesier B, Nong VH (1995) Crystal structure of narbonin at 1.8-angstrom resolution. Acta Crysta D51:177-189

Henrissat B (1991) A classification of glycosyl hydrolases based on amino acid sequence similarities. Biochem J 280:309-316

Huynh QK, Hironaka CM, Levine EB, Smith CE, Borgmeyer JR, Shah DM (1992) Antifungal proteins from plants. Purification, molecular cloning, and antifungal properties of chitinases from maize seed. J Biol Chem 267:6635-6640

Ishihara A, Miyagawa H, Matsukawa T, Ueno T, Mayama S, Iwamura $\mathrm{H}$ (1988) Induction of hydroxyanthranilate hydroxycinnamoyl transferase activity of oligo- $N$-acetylchitooligosaccharides in oats. Phytochemistry (Oxford) 47:929-974

Kasprzewska A (2003) Plant chitinases-regulation and function. Cell Mol Biol Lett 8:809-824

Lorito M (1998) Chitinolytic enzymes and their genes. In: Harman GE, Kubicek CP (eds) Trichoderma and Gliocladium, vol 2. Taylor and Francis, London, pp 73-99

Lorito M, Di Pietro A, Hayes CK, Woo SL, Harman GE (1993a) Antifungal, synergistic interaction between chitinolytic enzymes from Trichoderma harzianum and Enterobacter cloacae. Phytopathology 83:721-728

Lorito M, Harman GE, Hayes C, Broadway R, Tronsmo A, Woo SL, Di Pietro A (1993b) Chitinolytic enzymes produced by Trichoderma harzianum: antifungal activity of endochitinase and chitobiosidase. Phytopathology 83:302-307

Lorito M, Hayes CK, Peterbauer C, Tronsmo A, Klemsdal S, Harman GE (1993c) Antifungal chitinolytic enzymes from Trichoderma harzianum and Gliocladium virens: purification, characterization, biological activity and molecular cloning. In: Muzzarelli RAA (ed) Chitin enzymology, European Chitin Society, Ancona, pp 383-392

Lorito M, Peterbauer C, Hayes CK, Harman GE (1994) Synergistic interaction between fungal cell wall degrading enzymes and different antifungal compounds enhances inhibition of spore germination. Microbiology 140:623-629

Lorito M, Woo SL, Filippone E, Colucci G, Scala F (1996) Expression in plants of genes from mycoparasitic fungi-a new strategy for biological control of fungal diseases. International Union of Microbiological Societies (IUMS) Congresses, Jerusalem

Lorito M, Woo SL, Garcia Fernandez I, Colucci G, Harman GE, Pintor-Toro JA, Filippone E, Muccifora S, Lawrence CB, Zoina A, Tuzun S, Scala F (1998) Genes from mycoparasitic fungi as a source for improving plant resistance to fungal pathogens. Proc Natl Acad Sci USA 95:7860-7865

Mauch F, Mauch-Mani B, Boller T (1988) Antifungal hydrolases in pea tissue. II. Inhibition of fungal growth by combinations of chitinase and $\beta-1,3$ glucanase. Plant Physiol 88:936-942

Nakazaki T, Tsukiyama T, Okumoto Y, Kageyama D, Naito K, Inouye K, Tanisaka T (2006) Distribution, structure, organspecific expression and phylogenic analysis of the pathogenesis related protein-3 chitinase family in rice (Oryza sativa L.). Genome 49:619-630

Neuhaus JM (1999) Plant chitinases (PR-3, PR-4, PR-8, PR-11). In: Datta SK, Muthukrishnan S (eds) Pathogenesis-related proteins in plants, CRC press, Boca Raton, pp 77-105

Neuhaus J-M, Ahl-Goy P, Hinz U, Flores S, Meins F Jr (1991a) Highlevel expression of a tobacco chitinase gene in Nicotiana sylvestris. Susceptibility of transgenic plants to Cercospora nicotianae infection. Plant Mol Biol 16:141-151 
Neuhaus J-M, Sticher L, Meins FJ, Boller T (1991b) A short C-terminal sequence is necessary and sufficient for the targeting of chitinases to the plant vacuole. Proc Natl Acad Sci 88:10362-10366

Nong VH, Schlesier B, Bassüner R, Repik A, Horstmann C, Müntz K (1995) Narbonin, a novel 2S protein from Vicia narbonensis L. seeds: cDNA, gene structure and developmentally regulated formation. Plant Mol Biol 28:61-72

Oikawa A, Itoh E, Ishihara A, Iwamura H (2003) Purification and characterization of beta- $N$-acetylhexosaminidase from maize seedlings. J Plant Physiol 160:991-999

Park CH, Kim S, Park JY, Ahn IP, Jwa NS, Im KH, Lee YH (2004) Molecular characterization of a pathogenesis-related protein 8 gene encoding a class III chitinase in rice. Mol Cells 17:144-150

Passarinho PA, de Vries SC (2002) Arabidopsis chitinases: a genomic survey. In: Somerville CR, Meyerowitz EM (eds) The Arabidopsis book, American Society of Plant Biologists, Rockville, pp 1-25

Patil VR, Widholm JM (1997) Possible correlation between increased vigour and chitinase activity expression in tobacco. J Exp Bot 48:1943-1950

Poulton JE, Thomas MA, Ottwell KK, McCormick SJ (1985) Partial purification and characterization of a beta- $N$-acetylhexosaminidase from black cherry (Prunus serotina EHRH.) seeds. Plant Sci 42:107-114

Samac DA, Shah DM (1994) Effect of chitinase antisense RNA expression on disease susceptibility of Arabidopsis plants. Plant Mol Biol 25:587-596

Schlumbaum A, Mauch F, Vogeli U, Boller T (1986) Plant chitinases are potent inhibitors of fungal growth. Nature 324:365-367

Schultze M, Staehelin C, Brunner F, Genetet I, Legrand M, Fritig B, Kondorosi E, Kondorosi A (1998) Plant chitinase/lysozyme isoforms show distinct substrate specificity and cleavage site preference towards lipochitooligosaccharide Nod signals. Plant J $16: 571-580$

Sela-Buurlage MB, Ponstein AS, Bres-Vloemans SA, Melchers LS, van den Elzen PJM, Cornelissen BJC (1993) Only specific tobacco (Nicotiana tabacum) chitinases and beta-1, 3-glucanases exhibit antifungal activity. Plant Physiol 101:857-863

Shoresh M, Harman GE (2008) Differential expression of maize chitinases in the presence or absence of Trichoderma harzianum strain $\mathrm{T} 22$. (in press)

Shoresh M, Yedidia I, Chet I (2005) Involvement of the jasmonic acid/ ethylene signaling pathway in the systemic resistance induced in cucumber by Trichoderma asperellum T203. Phytopathology 95:76-84
Suzukawa K, Yamagami T, Ohnuma T, Hirakawa H, Kuhara S, Aso Y, Ishiguro M (2003) Mutational analysis of amino acid residues involved in catalytic activity of a family 18 chitinase from tulip bulbs. Biosci Biotechnol Biochem 67:341-346

Tiffin P (2004) Comparative evolutionary histories of chitinase genes in the genus Zea and family Poaceae. Genetics 167:1331-1340

Trudel J, Asselin A (1989) Detection of chitinase activity after polyacrylamide gel electrophoresis. Anal Biochem 178:362-366

Trudel J, Asselin A (1994) Protein purification for microsequencing by sequential native and denaturing polyacrylamide gel electrophoresis: application to one chitinase. Anal Biochem 221:214-216

van der Holst PPG, Schlaman HRM, Spaink HP (2001) Proteins involved in the production and perception of oligosaccharides in relation to plant and animal development. Curr Opin Struct Biol 11:608-616

van Hengel AJ, Tadesse Z, Immerzeel P, Schols H, van Kammen A, de Vries SC (2001) $N$-Acetylglucosamine and glucosamine-containing arabinogalactan proteins control somatic embryogenesis. Plant Physiol 125:1880-1890

van Hengel AJ, van Kammen A, de Vries SC (2002) A relationship between seed development, Arabinogalactan-proteins (AGPs) and the AGP mediated promotion of somatic embryogenesis. Physiol Planta 114:637-644

Verburg JG, Smith CE, Lisek CA, Huynh QK (1992) Identification of an essential tyrosine residue in the catalytic site of a chitinase isolated from Zea mays that is selectively modified during inactivation with 1-ethyl-3-(3-dimethylaminopropyl)-carbodiimide. J Biol Chem 267:3886-3893

Verburg JG, Rangwala SH, Samac DA, Luckow VA, Huynh QK (1993) Examination of the role of tyrosine-174 in the catalytic mechanism of the Arabidopsis thaliana chitinase: comparison of variant chitinases generated by site-directed mutagenesis and expressed in insect cells using baculovirus vectors. Arch Biochem Biophys 300:223-230

Watanabe T, Kobori K, Miyashita K, Fujii T, Sakai H, Uchida M, Tanaka H (1993) Identification of glutamic acid 204 and aspartic acid 200 in chitinase A1 of Bacillus circulans WL-12 as essential residues for chitinase activity. J Biol Chem 268:18567-18572

Wu S, Kriz AL, Widholm JM (1994) Molecular analysis of two cDNA clones encoding acidic class I chitinase in maize. Plant Physiol 105:1097-1105

Yokoyama R, Nishitani K (2004) Genomic basis for cell-wall diversity in plants. A comparative approach to gene families in rice and Arabidopsis. Plant Cell Physiol 45:1111-1121 